\title{
Publisher's Note: Hilbert transform: Applications to atomic spectra [Phys. Rev. A 91, 032513 (2015)]
}

Kate A. Whittaker, James Keaveney, Ifan G. Hughes, and Charles S. Adams

(Received 16 November 2015; published 30 November 2015)

DOI: 10.1103/PhysRevA.92.059904

PACS number(s): 32.30.-r, 32.70.-n, 31.15.-p, 99.10.Fg

This paper was published online on 25 March 2015 with a typographical error in Eq. (3). Equation (3) should read as

$$
\chi_{\mathrm{R}}(\omega)=\frac{2}{\pi} \int_{0}^{\infty} \frac{\omega^{\prime} \chi_{\mathrm{I}}\left(\omega^{\prime}\right)}{\omega^{\prime 2}-\omega^{2}} d \omega^{\prime}
$$

The equation has been corrected as of 16 November 2015. The equation is incorrect in the printed version of the journal. 